\title{
Fragrances and Aerosol during Office Cleaning
}

\author{
Aikaterini Maria Zarogianni, Glykeria Loupa*, Spyridon Rapsomanikis \\ Laboratory of Atmospheric Pollution and of Control Engineering of Atmospheric Pollutants, Faculty of Engineering, \\ Department of Environmental Engineering, Democritus University of Thrace, 67100 Xanthi, Greece
}

\begin{abstract}
Fragrance compounds emitted during and after the use of cleaning products in an office were monitored. Mopping the floor with a general purpose cleaner and a domestic bleach and cleaning the windows with an aerosol glass cleaner, as well as a combination of these cleaning activities, were carried out. The following compounds were found in detectable amounts: d-limonene, $\alpha$-pinene, $\alpha$-terpineol, 2-butoxyethanol, 1,3,5-trimethylbenzene, eucalyptol, tetrahydrolinalool and diphenyl ether.

Along with the fragrances, the number concentrations of airborne particles with an aerodynamic diameter range between $0.2 \mu \mathrm{m}$ and $10 \mu \mathrm{m}$ were monitored continuously. Cleaning affected the number concentrations of all particle sizes, but particles with an aerodynamic diameter above $0.4 \mu \mathrm{m}$ were the most affected. The largest increase above background concentrations was observed during mopping the floor with a solution of general purpose cleaner in combination with cleaning the windows with a glass-cleaning spray. In this case, for particles larger than $0.4 \mu \mathrm{m}$, indoor number concentrations were 19 times larger than the background concentrations. Conversely, for particles below $0.4 \mu \mathrm{m}$, number concentrations increased only 4 times above the background concentrations during the same event. Auxiliary measurements included carbon dioxide $\left(\mathrm{CO}_{2}\right)$ concentrations and the indoor micro-climatic conditions (air velocity, light intensity, temperature and relative humidity).
\end{abstract}

Keywords: Household cleaning products; Mopping; Window cleaning; Terpenes; Particles.

\section{INTRODUCTION}

Cleaning products contain numerous chemicals that can be released in the indoor atmosphere during and after a cleaning activity (Wolkoff et al., 1998; Nørgaard et al., 2014). Fragrances that have been added during the manufacturing process of the cleaning products either deliver a scent in the air or mask the unpleasant odour of the product. We have analysed qualitatively the fragrance content of several detergents by gas chromatography coupled with mass spectrometry (GC/MS) (Zarogianni et al., 2017). It was found that non-green household cleaning products as well as green ones (certified with EU Ecolabel) contain numerous fragrances. Some of these compounds common in both products (e.g., lauryl alcohol).

Fragrances, like terpenes or terpene alcohols, react with $\mathrm{O}_{3}, \mathrm{OH}$ and $\mathrm{NO}_{3}$ producing several by-products through gas-phase reactions or reactions on surfaces (Nazaroff and Weschler, 2004; Ham and Wells, 2011; Rösch et al., 2017).

\footnotetext{
* Corresponding author.

Tel: +30-25410 79314; Fax: +30-25410 79379

E-mail address: gloupa@env.duth.gr
}

Some of the primary or secondary products of such reactions are low-volatility species that can condense on existing aerosols or self-nucleate, thus generating secondary organic aerosol (SOA). The role of monoterpenes on the formation of secondary atmospheric pollutants is extensively reviewed by Mihucz and Záray (2016). There is a growing concern about the human exposure to fragrances and/or their by-products like SOA, because they may be deleterious to human health (Mihucz and Záray, 2016). Recently, Nørgaard et al. (2014) reported that the replacement of the regular floor cleaning agent with a lower emitting TVOC, resulted in substantially lower concentrations of limonene and formaldehyde in the indoor atmosphere of four European offices. Also, Steinemann (2016) has suggested that fragranced cleaning products are a primary source of indoor air pollutants and personal exposure.

Indoor cleaning activities emit particles, as well as forming particles via gas-phase reactions. The size and the chemical composition of the emitted or generated aerosol depends on the chemical composition and the type of the cleaning product (e.g., liquid or spray), the type of the surfaces that have to be cleaned and the product application procedure (e.g., wet or dry cleaning) (Abt et al., 2000; Smedje and Norbäck, 2001; Vu et al., 2017). The latter, Vu et al. (2017), have monitored PM number concentrations 
in an apartment located in the suburban background of Prague, Czech Republic, under realistic conditions like in the present work. During the kitchen desk cleaning with the application of a foam containing organic compounds, they observed the generation of ultrafine particles with a maximum concentration of $1.25 \times 10^{5}$ particle $\mathrm{cm}^{-3}$ and a peak number mode of $30.6 \mathrm{~nm}$. This PM number concentration was observed to decrease rapidly due to coagulation and deposition processes after the termination of the cleaning activity. Furthermore, they reported that cleaning with chemical cleaners generated both ultrafine and coarse particles. The average $\mathrm{PM}_{1.0}, \mathrm{PM}_{2.5}$ and $\mathrm{PM}_{10}$ mass concentration (estimated from the merged size distribution from two instruments and effective density) during cleaning activity were $2.5,10.4$ and $22.0 \mu \mathrm{g} \mathrm{m} \mathrm{m}^{-3}$, respectively. Rossignol et al. (2013) have monitored the indoor PM number and mass concentrations in the "MARIA" experimental house during the application of cleaning products, under real conditions. They have reported an initial (when the product was applied) increase of PM mass concentrations, which reached $25.6 \mu \mathrm{g} \mathrm{m}^{-3}$ and corresponded to primary, mainly coarse, PM emissions. Later, after $15 \mathrm{~min}$, SOA were formed, displaying a mode at $25 \mathrm{~nm}$. In a European project, the "OFFICAIR", a reference dataset for indoor concentrations of several indoor air pollutants, including $\alpha$-pinene, $\mathrm{d}$-limonene and $\mathrm{PM}_{2.5}$, is provided for "modern" mechanically-ventilated office buildings in 8 European countries (Mandin et al., 2017). The concentrations of $\alpha$-pinene and d-limonene were found to be higher than those reported in similar studies. Indoor concentrations of $\mathrm{PM}_{2.5}$ in the offices have been found to be high when compared to the 24-h $\left(25 \mu \mathrm{g} \mathrm{m}^{-3}\right)$ and annual $\left(10 \mu \mathrm{g} \mathrm{m}^{-3}\right)$ ambient air quality guidelines for $\mathrm{PM}_{2.5}$ suggested by the World Health Organization (WHO, 2006).

Exposure to PM is related to poor health (cardiovascular disease, adverse birth outcomes, neurological and cognitive disorders), as well as premature mortality (Butler et al., 2016; Giannadaki et al., 2016; Long and Valberg, 2017; Soppa et al., 2017). Furthermore, Boulanger et al. (2017) evaluated the socio-economic costs of indoor air pollution in France. Among the six selected indoor atmospheric pollutants related to health effects, particles contributed the most to the total cost $(75 \%)$. Air quality guidelines refer to PM mass concentration, but the size distribution and the PM number concentrations are critical parameters to trace indoor PM sources and their possible health effects (Strak et al., 2012; Vu et al., 2017).

The present work aims to explore the concentration burden of the fragrances and of the PM in the indoor air of an office that is subjected to common cleaning activities using scented cleaning products.

\section{METHODS}

Two common cleaning tasks were carried out in an office during June 2014 (3-23 June): floor cleaning (dipping the mop into a bucket filled either with water or with a cleaning solution) and window cleaning. The products that were applied were among the most popular products used in Greek households and they were: a General Purpose Cleaner (GPC), a Domestic Bleach (DB) and a Glass Cleaner (GC) spray. All of them are fragranced and on the label of the GPC is written "lavender", of the DB "lemon" and on the GC only the word "perfume".

Firstly, the office was mopped up only with water for $10 \mathrm{~min}$. In the following days, five cleaning tasks were performed. The first task was an 8-min mopping of $6 \mathrm{~m}^{2}$ surface of the floor with a dilution of the GPC (56 $\mathrm{ml}$ of the GPC in a bucket containing $5 \mathrm{~L}$ of tap water, following the instructions on the label of the product). The second task was the cleaning of the three windows for a 15 -min period with the GC, by spraying the product about $20 \mathrm{~cm}$ away from the glass and the latter wiped with a paper towel. The third task was an 8-min mopping of $6 \mathrm{~m}^{2}$ surface of the floor with a dilution of the DBC $(150 \mathrm{~mL}$ of the GPC in a bucket containing $5 \mathrm{~L}$ of tap water, according to the product's instructions). The fourth was a combined application of GPC and GC and finally, the fifth was a combined application of DB and GC.

The office is naturally ventilated and the floor has plastic tiles and no carpeting. Windows and the door were kept closed during the experiments and they were opened for two hours in the evening.

Active sampling of fragrances was combined with the online monitoring of indoor and outdoor PM size distribution and number concentrations of particles with aerodynamic diameter from $0.20 \mu \mathrm{m}$ to $10 \mu \mathrm{m}$ (Promo 2000 particle, Palas $\mathrm{GmbH}$, Germany). Also, indoor and outdoor $\mathrm{CO}_{2}$ concentrations (Gas Card II, infrared gas monitor, Edinburgh Sensors, UK), as well as indoor temperature, relative humidity, air velocity and light intensity (Casella CEL Ltd., UK) were monitored.

The office layout, the air sampling of fragrances, the methods for fragrance quantification and the detection limit of the each identified compound, as well as the air exchange rate calculation can be found in the supplementary material.

\section{RESULTS AND DISCUSSION}

\section{Fragrance Concentrations}

The fragrances detected in the atmosphere of the office during and after the cleaning tasks are summarized in the Table 1. $\alpha$-pinene was the most frequently occurring fragrance in the air samples and 1,3,5-trimethylbenzene $(1,3,5-\mathrm{TMB})$ was second in frequency of occurrence. Dlimonene had the largest atmospheric concentrations followed by $\alpha$-pinene. Both terpenes are very popular ingredients in consumer products worldwide. Note, that none of them was detected in the atmosphere of the office before the experiments and none of them was recorded on the label of the tested products.

Fig. 1 presents an example of the time-variation of the concentrations of two fragrances during four cleaning events (their limits of detection can be found in the supplementary material). Mopping with a GPC in combination with the cleaning of the windows by spraying with a GC, added to the indoor air the maximum number of fragrances. The 
Table 1. A summary of the cleaning tasks and detected fragrances with their maximum atmospheric concentrations (ppbv).

\begin{tabular}{|c|c|c|c|c|c|}
\hline & \multicolumn{2}{|c|}{ Mopping } & \multirow{2}{*}{$\begin{array}{l}\text { Cleaning the windows } \\
{ }^{*} \mathrm{GC}\end{array}$} & \multicolumn{2}{|c|}{ Mopping and cleaning the windows } \\
\hline & *GPC & ${ }^{*} \mathrm{DB}$ & & GPC and GC & $\mathrm{DB}$ and $\mathrm{GC}$ \\
\hline$\alpha$-pinene & 46.21 & 44.52 & nd & 47.81 & 46.33 \\
\hline $1,3,5-\mathrm{TMB}$ & 0.30 & 0.79 & 0.76 & 0.93 & 0.98 \\
\hline d-limonene & 1625.2 & nd & nd & 1625.5 & nd \\
\hline Eucalyptol & 3.12 & 1.20 & nd & 3.62 & 1.80 \\
\hline Tetrahydrolinalool & ${ }^{* *}$ nd & 0.73 & nd & 0.24 & 0.94 \\
\hline$\alpha$-Terpineol & 9.12 & nd & nd & 10.41 & nd \\
\hline Diphenyl ether & 0.09 & nd & nd & 0.10 & nd \\
\hline 2-BE & nd & nd & 24.12 & 20.31 & 18.32 \\
\hline
\end{tabular}

*GPC $=$ General-purpose cleaner; DB = Domestic bleach; $\mathrm{GC}=$ Glass cleaner (spray).

${ }^{* *}$ nd $=$ not detected.
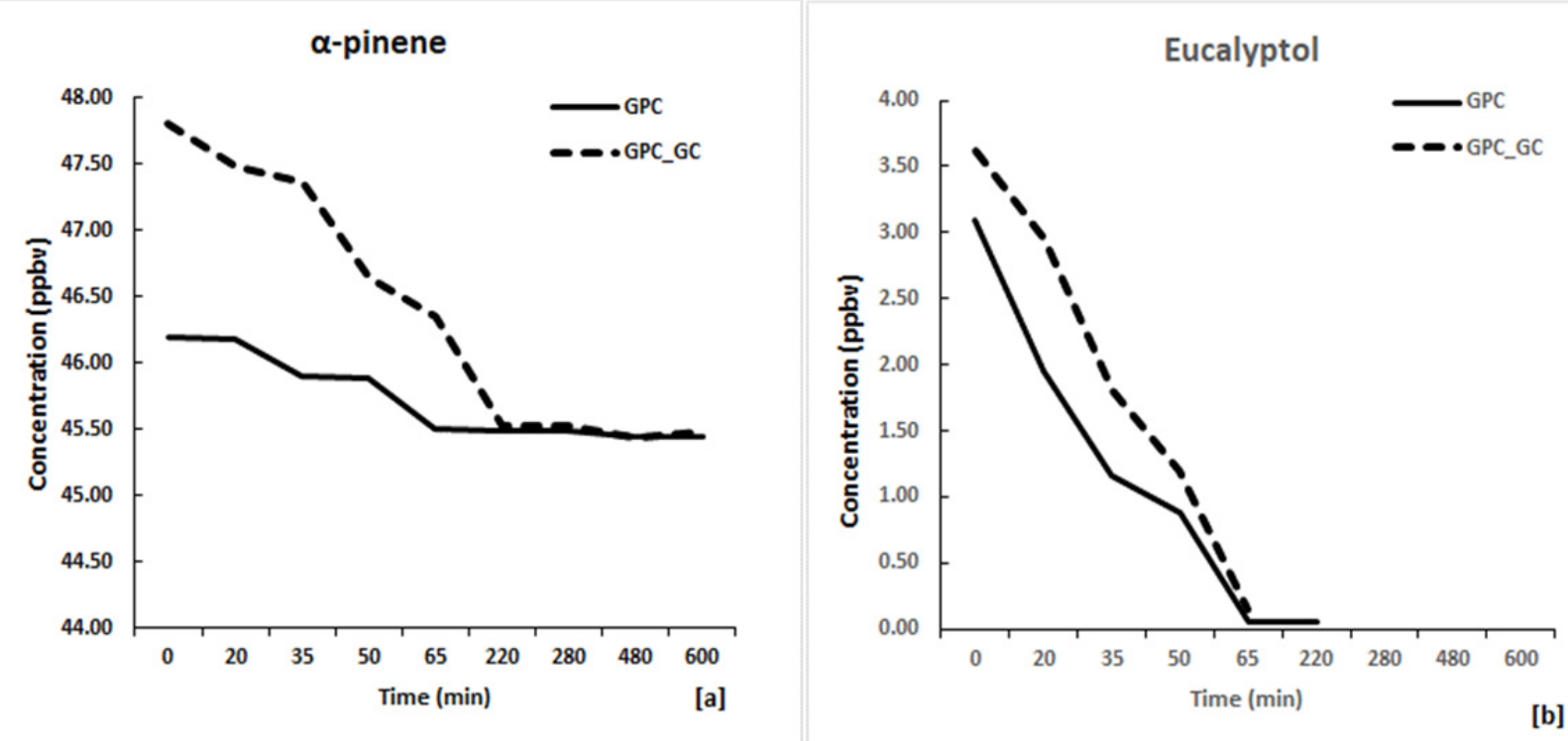

Fig. 1. Comparison of two fragrance concentrations in the office, during and after cleaning tasks.

detected fragrance concentrations decayed after each cleaning task. The decay rate of the emitted fragrances depended on their initial concentration found in the room during the product application, their individual chemical characteristics and the air exchange rate of the room. Some of them, such as eucalyptol, were not detected in the indoor atmosphere in a half hour or in an hour after cleaning. Others, like $\alpha$-pinene or d-limonene with much higher initial concentrations, decayed much slower than eucalyptol and they were traced in the air at least for five hours after the cleaning task.

During the sampling period the weather was very hot and sunny. Indoor temperature hourly values ranged between $29.1^{\circ} \mathrm{C}$ and $40.4^{\circ} \mathrm{C}$ and the indoor $\mathrm{RH}$ between $22.0 \%$ and $43.8 \%$. The luminance, when the blinds of the windows were open, was up to 12,000 lux. Under these conditions, evaporation of fragrances was favored and the chemical reactions were accelerated. The air exchange rate of the room varied between $0.12 \mathrm{~h}^{-1}$ to $1.16 \mathrm{~h}^{-1}$ (average $0.43 \mathrm{~h}^{-1}$ ). SOA formation rate from $\mathrm{O}_{3}$-limonene or $\mathrm{O}_{3}$ - $\alpha$-pinene reactions was calculated to be higher than the air exchange rate (see calculations in the supplementary material, lines 94-109). Thus SOA were probably generated by oxidation and condensation of the released terpenes during the cleaning activity (Nørgaard et al., 2014). However, the production of nano and/or ultrafine particles was not possible to be traced due to the limitation of the instrumentation used in the present work (Vu et al., 2017).

\section{PM Number Concentrations, Size Distributions and I/O Ratios}

Depicted in Fig. 2 is the variation of the fine PM, i.e., $\mathrm{PM}_{0.2-1.0}$ (particulate matter with a diameter between $0.2 \mu \mathrm{m}-1.0 \mu \mathrm{m}$ ), during the experiment. Particles in these sizes may be more deleterious to human health than the larger in diameter particles. Their study necessitated the split in two size ranges with a cut-off point at $0.4 \mu \mathrm{m}$ because it was observed that the time variation of the PM concentrations was similar for particles than belong to size ranges smaller than $0.4 \mu \mathrm{m}$ in diameter and for PM in size ranges larger than $0.4 \mu \mathrm{m}$. Hence, Figs. 2(a) and 2(b) depicts the indoor $\mathrm{PM}_{0.2-0.4}$ and $\mathrm{PM}_{0.4-1.0}$ concentration time-series during two Sundays (15 June 2014 and 22 June 2014). On 22 June 2014, PM concentrations were the lowest observed during the period of experiments, because no cars were 

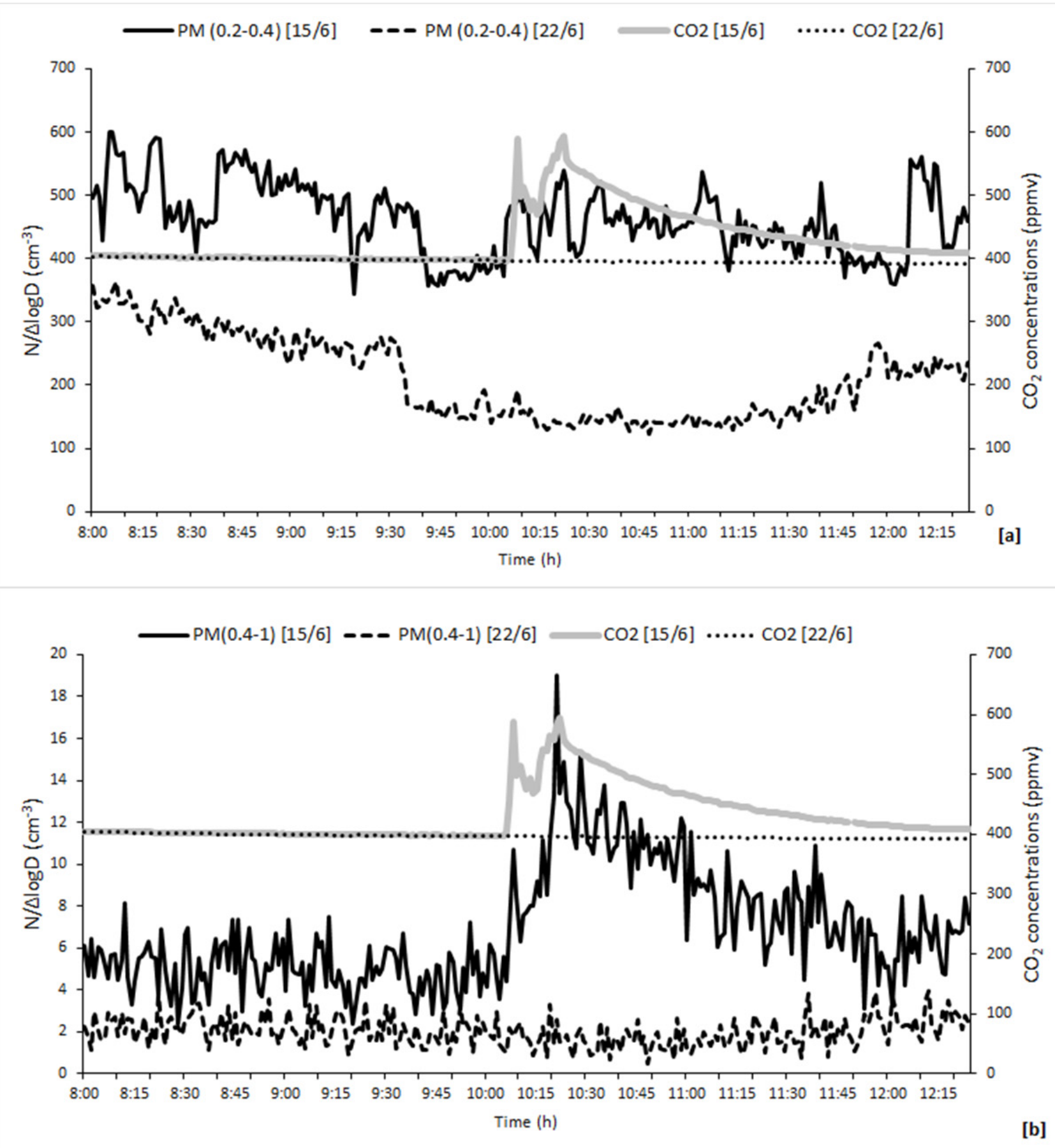

Fig. 2. Comparison of fine $\mathrm{PM}$ number concentrations and $\mathrm{CO}_{2}$ concentrations between two days, one with cleaning activity and the other without any activity.

arriving in the yard and in the building itself indoor activities were almost absent. On 15 June 2014, from 10:04 till 10:14, a researcher cleaned two windows and for the next 6 minutes the floor was mopped with water and bleach. The simultaneous indoor $\mathrm{CO}_{2}$ concentration measurements helped (along with the diary of the experiment) to relate the increase of the indoor PM concentrations with the presence of one person which conducted the cleaning activities.

All measured PM size ranges were affected by the cleaning activities, but mostly affected were the PM larger than $0.4 \mu \mathrm{m}$ in diameter. On average, during all the cleaning events, the PM number concentrations increase, compared with their preceding values (half an hour average values, just before the start of the cleaning), by $10 \%$ to $1270 \%$. The larger the particle diameter, the bigger was the observed increase. The walking-induced particle resuspension or direct skin shedding was a minor indoor PM source compared with the cleaning activities. In Fig. 3, the I/O PM number concentration ratios are compared between the different cleaning events. The mopping up with water plus a detergent 


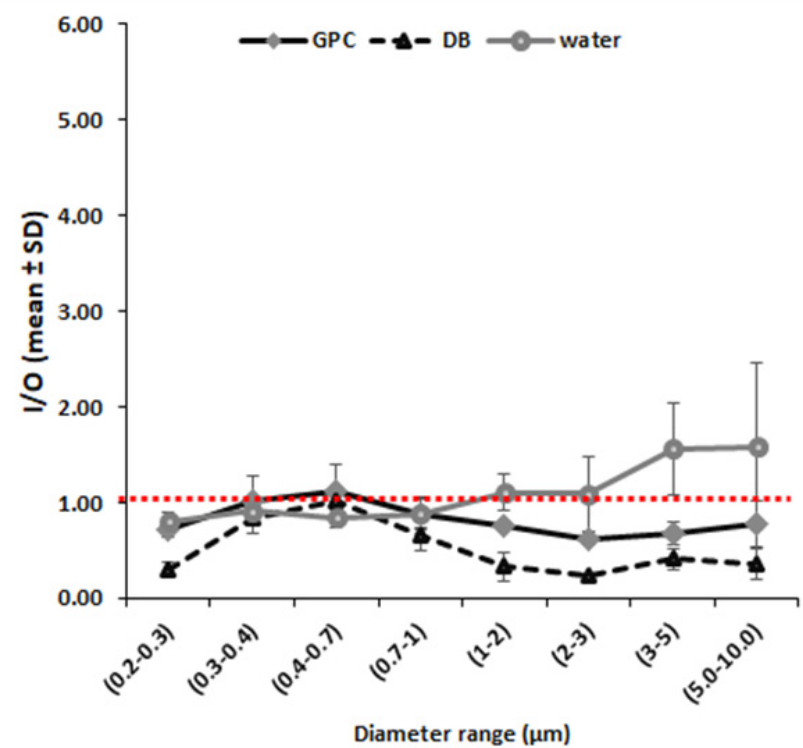

[a]

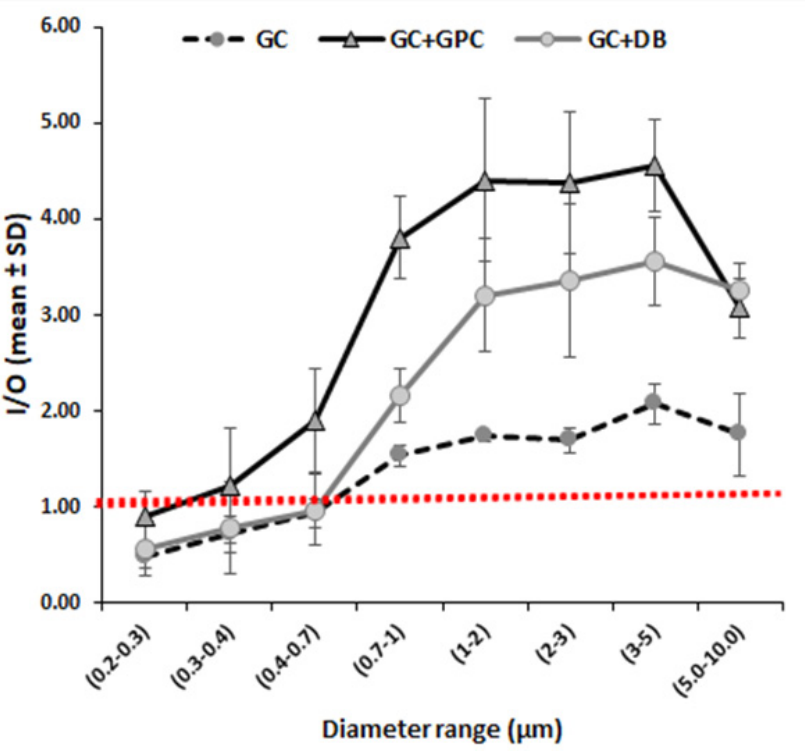

[b]

Fig. 3. I/O PM number concentration ratios during several cleaning events.

removed better the coarse PM (above $1.0 \mu \mathrm{m}$ ) compared with mopping up only with water (Fig. 3(a)). In the case of the cleaning of the windows, separately or combined with mopping up the floor, the maximum $\mathrm{I} / \mathrm{O}$ ratios shows a shift to larger particle diameters and the ratios for PM above $0.7 \mu \mathrm{m}$ in diameter were almost double than when only the floor was mopped up.

Indoor and outdoor PM mass concentrations were calculated using an average particle density of $1.7 \mathrm{~g} \mathrm{~cm}^{-3}$ (Hussein et al., 2015; Vu et al., 2017). Outdoor of the office, the $\mathrm{PM}_{0.2-2}$ and $\mathrm{PM}_{0.2-10}$ concentrations were on average $7.3 \mu \mathrm{g} \mathrm{m}^{-3}$ (S.D. $=1.0 \mu \mathrm{g} \mathrm{m}^{-3}$ ) and $39.2 \mu \mathrm{g} \mathrm{m}^{-3}$ (S.D. $=9.8 \mu \mathrm{g} \mathrm{m}^{-3}$ ), respectively, during working hours. The indoor half an hour average mass concentrations (just before cleaning, empty office) of $\mathrm{PM}_{0.2-2}$ and $\mathrm{PM}_{0.2-10}$ were: $5.4 \mu \mathrm{g} \mathrm{m}^{-3}$ (S.D. $=0.9 \mu \mathrm{g} \mathrm{m}^{-3}$ ) and $7.8 \mu \mathrm{g} \mathrm{m}^{-3}$ (S.D. $=$ $3.2 \mu \mathrm{g} \mathrm{m}^{-3}$ ), respectively. During the cleaning activities, the $\mathrm{PM}_{0.2-2}$ concentrations ranged between $4.8 \mu \mathrm{g} \mathrm{m}^{-3}$ to $8.9 \mu \mathrm{g} \mathrm{m}^{-3}$ and the $\mathrm{PM}_{0.2-10}$ concentrations ranged between $20.5 \mu \mathrm{g} \mathrm{m}^{-3}$ and $112.7 \mu \mathrm{g} \mathrm{m}^{-3}$. The present results are comparable with those reported by $\mathrm{Vu}$ et al. (2017) and Rossignol et al. (2013) during cleaning activities.

\section{CONCLUSIONS}

Office cleaning aims to provide a level of indoor air quality that promotes health and productivity. However, the activities of cleaning and refreshing are not necessarily related to clean air. Common cleaning practices, such as mopping the floor and spraying windows with a glass cleaner, burden the air with fragrances and aerosol. Based on the decay rates observed in the present work for fragrances and aerosol, cleaning should be finished at least five hours before people enter the room. The selection of cleaning products is also important, as some ingredients promote the subsequent formation of oxygenated products (Ham and Wells, 2011). Although in the present work it was not feasible to monitor SOA formation or reactions on indoor surfaces, in cases where $\alpha$-terpineol was present, the maximum aerosol concentrations were observed. These results are in agreement with the work of Ham and Wells, 2011.

Experimentally examined best cleaning practices and carefully selected cleaning products will minimize the burden of air pollutants.

\section{ACKNOWLEDGMENTS}

We thank Bodossaki Foundation, Athens, Greece, for financially supporting one of the authors with a studentship.

\section{SUPPLEMENTARY MATERIAL}

Supplementary data associated with this article can be found in the online version at http://www.aaqr.org.

\section{REFERENCES}

Abt, E., Suh, H.H., Allen, G. and Koutrakis, P. (2000). Characterization of indoor particle sources: A study conducted in the metropolitan boston area. Environ. Health Perspect. 108: 35-44.

Boulanger, G., Bayeux, T., Mandin, C., Kirchner, S., Vergriette, B., Pernelet-Joly, V. and Kopp, P. (2017). Socio-economic costs of indoor air pollution: A tentative estimation for some pollutants of health interest in france. Environ. Int. 104: 14-24.

Butler, D.A., Madhavan, G. and Alper, J. (2016). Health risks of indoor exposure to particulate matter: Workshop summary. National Academies Press, Washington, DC. 
Giannadaki, D., Lelieveld, J. and Pozzer, A. (2016). Implementing the us air quality standard for $\mathrm{PM}_{2.5}$ worldwide can prevent millions of premature deaths per year. Environ. Health 15: 88.

Ham, J.E. and Wells, J.R. (2011). Surface chemistry of a pine-oil cleaner and other terpene mixtures with ozone on vinyl flooring tiles. Chemosphere 83: 327-333.

Hussein, T., Dada, L., Juwhari, H. and Faouri, D. (2015). Characterization, fate, and re-suspension of aerosol particles $(0.3-10 \mu \mathrm{m})$ : The effects of occupancy and carpet use. Aerosol Air Qual. Res. 15: 2367-2377.

Long, C.M. and Valberg, P.A. (2017). Indoor airborne particulate matter: Unregulated, but a major contributor to our everyday exposure. Nat. Resour. Environ. 32: 812 .

Mandin, C., Trantallidi, M., Cattaneo, A., Canha, N., Mihucz, V.G., Szigeti, T., Mabilia, R., Perreca, E., Spinazzè, A., Fossati, S., De Kluizenaar, Y., Cornelissen, E., Sakellaris, I., Saraga, D., Hänninen, O., De Oliveira Fernandes, E., Ventura, G., Wolkoff, P., Carrer, P. and Bartzis, J. (2017). Assessment of indoor air quality in office buildings across Europe - The OFFICAIR study. Sci. Total Environ. 579: 169-178.

Mihucz, V.G. and Záray, G. (2016). Chapter 3 - indoor air pollution, In Comprehensive analytical chemistry, de la Guardia, M. and Armenta, S. (Eds.), Elsevier, pp. 4571.

Nazaroff, W.W. and Weschler, C.J. (2004). Cleaning products and air fresheners: Exposure to primary and secondary air pollutants. Atmos. Environ. 38: 28412865.

Nørgaard, A.W., Kofoed-Sørensen, V., Mandin, C., Ventura, G., Mabilia, R., Perreca, E., Cattaneo, A., Spinazzè, A., Mihucz, V.G., Szigeti, T., De Kluizenaar, Y., Cornelissen, H.J.M., Trantallidi, M., Carrer, P., Sakellaris, I., Bartzis, J. and Wolkoff, P. (2014). Ozone-initiated terpene reaction products in five european offices: Replacement of a floor cleaning agent. Environ. Sci. Technol. 48: 13331-13339.

Rösch, C., Wissenbach, D.K., Franck, U., Wendisch, M. and Schlink, U. (2017). Degradation of indoor limonene by outdoor ozone: A cascade of secondary organic aerosols. Environ. Pollut. 226: 463-472.

Rossignol, S., Rio, C., Ustache, A., Fable, S., Nicolle, J., Même, A., D'Anna, B., Nicolas, M., Leoz, E. and
Chiappini, L. (2013). The use of a housecleaning product in an indoor environment leading to oxygenated polar compounds and SOA formation: Gas and particulate phase chemical characterization. Atmos. Environ. 75: 196-205.

Smedje, G. and Norbäck, D. (2001). Irritants and allergens at school in relation to furnishings and cleaning. Indoor Air 11: 127-133.

Soppa, V.J., Schins, R.P.F., Hennig, F., Nieuwenhuijsen, M.J., Hellack, B., Quass, U., Kaminski, H., Sasse, B., Shinnawi, S., Kuhlbusch, T.A.J. and Hoffmann, B. (2017). Arterial blood pressure responses to short-term exposure to fine and ultrafine particles from indoor sources - A randomized sham-controlled exposure study of healthy volunteers. Environ. Res. 158: 225-232.

Steinemann, A. (2016). Fragranced consumer products: Exposures and effects from emissions. Air Qual. Atmos. Health 9: 861-866.

Strak, M., Janssen, N.A.H., Godri, K.J., Gosens, I., Mudway, I.S., Cassee, F.R., Lebret, E., Kelly, F.J., Harrison, R.M., Brunekreef, B., Steenhof, M. and Hoek, G. (2012). Respiratory health effects of airborne particulate matter: the role of particle size, composition, and oxidative potential-the RAPTES project. Environ. Health Perspect. 120: 1183-1189.

Vu, T.V., Ondracek, J., Zdímal, V., Schwarz, J., DelgadoSaborit, J.M. and Harrison, R.M. (2017). Physical properties and lung deposition of particles emitted from five major indoor sources. Air Qual. Atmos. Health 10: $1-14$.

WHO (2006). Air quality guidelines: Global update 2005. Particulate matter, ozone, nitrogen dioxide and sulfur dioxide. World Health Organization.

Wolkoff, P., Schneider, T., Kildesø, J., Degerth, R., Jaroszewski, M. and Schunk, H. (1998). Risk in cleaning: Chemical and physical exposure. Sci. Total Environ. 215: 135-156.

Zarogianni, A.M., Loupa, G. and Rapsomanikis, S. (2017). A comparison of fragrance ingredients in green and nongreen detergents. Environ. Forensics 18: 110-121.

Received for review, August 13, 2017

Revised, December 13, 2017 Accepted, March 7, 2018 